\title{
pH-metric Studies and Electrochemical Behavior of Eu(III)-7- carboxymethoxy-4-methylcoumarin with 5'-GMP
}

\author{
Amin A. Seleem ${ }^{1,3, *}$, Belal H.M.Hussein ${ }^{2,4, *}$, Walid Fathalla ${ }^{5}$, and Sherin A. Ali ${ }^{6}$ \\ ${ }^{1}$ Department of Biology, Faculty of Science and Arts, Al Ula, Taibah University, KSA \\ ${ }^{2}$ Department of Chemistry, Faculty of Science and Arts, Al Ula, Taibah University, KSA \\ ${ }^{3}$ Zoology Department, Faculty of Science, Sohag University, Egypt \\ ${ }^{4}$ Department of Chemistry, Faculty of Science, Suez Canal University, Ismailia, Egypt \\ ${ }^{5}$ Department of Mathematical and Physical Sciences, Faculty of Engineering, Port-Said University, \\ Port-Said, Egypt \\ ${ }^{6}$ Department of Mathematical and Physical Sciences, Faculty of Engineering, Suez Canal University, \\ Ismailia, Egypt \\ *E-mail: amin_seleem@yahoo.com, belalhussein102@yahoo.com
}

doi: $10.20964 / 2018.04 .05$

Received: 6 Decemebr 2017 / Accepted: 27 January 2018 / Published: 6 March 2018

\begin{abstract}
The interaction of Eu(III)-7-carboxymethoxy-4-methylcoumarin(CMMC) with guanosine-5'momophosphate (5'-GMP) has been investigated using electron analytical, fluorescence, and potentiometric methods in the ethanol-water mixture solvent ( 0.15 volume fraction). The formation of the different binary, ternary, and quaternary complexes is confirmed by the corresponding $\mathrm{pH}$ potentiometric curves. SUPERQUAD computer program has been used for the refinement of all the calculated constants in our present study. Electroanalytical techniques have been used to confirm the formation of different binary and ternary complexes under investigation. The binding constant of the ternary complex Eu(III)-CMMC-5'-GMP calculated by fluorescence technique was found to be $1.8 \mathrm{x}$ $10^{7}$ with 1:1 molar ratio. DNA cleavage properties of the CMMC, gibberellic acid, and their europium complexes were tested by gel electrophoresis.
\end{abstract}

Keywords: Potentiometry; Eu(III)-7-carboxymethoxy-4-methylcoumarin (CMMC); 5'-GMP binding properties; Voltammetry; Fluorescence spectroscopy.

\section{$\underline{\text { FULL TEXT }}$}

(C) 2018 The Authors. Published by ESG (www.electrochemsci.org). This article is an open access article distributed under the terms and conditions of the Creative Commons Attribution license (http://creativecommons.org/licenses/by/4.0/). 